DOI: $\underline{\text { https://doi.org/10.32663 }}$

\title{
PERSEPSI MASYARAKAT KELURAHAN WELAI TIMUR DAN KELURAHAN WELAI BARAT TENTANG REHABILITASI DAN PENGELOLAAN HUTAN MANGROVE
}

\author{
Tyas Dita Pramesthy ${ }^{1}$, Jahved Feriyanto Maro ${ }^{2}$ \\ ${ }^{1}$ Politeknik Kelautan dan Perikanan Dumai, Jl. Wan Amir No. 1, Pangkalan Sesai, Kota Dumai, \\ Riau, Indonesia, 28826. \\ ${ }^{2}$ Fakultas Pertanian dan Perikanan Universitas Tribuana Kalabahi, Jl. Tang'eng, Kab. Alor, \\ Nusa Tenggara Timur, Indonesia, 85812. \\ *Corresponding Author, Email: tyasdtpramesthy@gmail.com
}

\begin{abstract}
Mangrove forest is a coastal vegetation that has unique characteristics. The role of mangrove forests in addition to their ecological functions that are constructive, is also known to have economic values that encourage exploratory activities, so mangroves are vulnerable to destruction. The purpose of this study was to determine the rehabilitation and management of mangrove forests in Welai Timur Village and Welai Barat Village, Regency of Alor. This study uses a field survey method with explorative and data retrieval using questionnaires, analyzed using the Path Analysis SmartPLS. The results of the research through the path coefficients test show that the variables that have the greatest coefficient and t-count values are the aspirations and role of the community in the rehabilitation of mangrove forests compared with regional policy variables on aspirations and roles, as well as regional policies on the rehabilitation of mangrove forests in Welai Timur Village and Welai Barat Village.
\end{abstract}

Keywords: management, mangrove, rehabilitation.

\begin{abstract}
ABSTRAK
Hutan mangrove merupakan vegetasi pantai yang memiliki karakteristik yang unik. Peran hutan mangrove selain ditinjau dari fungsi ekologinya yang membangun, juga diketahui memiliki nilai ekonomis yang mendorong kegiatan eksploratif, sehingga mangrove rawan terhadap perusakan. Tujuan penelitian ini untuk mengetahui persepsi masyarakat terhadap rehabilitasi dan pengelolaan hutan mengrove di Kelurahan Welai Timur dan Kelurahan Welai Barat Kabupaten Alor. Penelitian ini menggunakan metode survei lapangan dengan eksploratif dan pengambilan data menggunakan kuesioner, di analisis menggunakan analisis jalur (Path Analysis) SmartPLS. Hasil penelitian melalui Uji Path menggambarkan bahwa variabel yang memiliki nilai koefisien dan nilai T-hitung terbesar adalah aspirasi dan peran masyarakat terhadap rehabilitasi hutan mangrove dibandingkan dengan variabel kebijakan daerah terhadap aspirasi dan peran masyarakat, juga kebijakan daerah terhadap rehabilitasi hutan mangrove di Kelurahan Welai Timur dan Kelurahan Welai Barat.
\end{abstract}

Kata kunci: mangrove, pengelolaan, rehabilitasi. 
DOI: $\underline{\text { https://doi.org/10.32663 }}$

\section{PENDAHULUAN}

Hutan mangrove merupakan vegetasi pantai yang memiliki karakteristik, tumbuh di daerah intertidal, jenis tanahnya berlumpur, berlempung atau berpasir, daerahnya tergenang air laut secara berkala, baik setiap hari maupun hanya tergenang pada saat pasang purnama, menerima pasokan air tawar yang cukup dari darat, terlindung dari gelombang arus besar dan arus pasang surut. Hutan mangrove dapat dibedakan ke dalam beberapa zonasi berdasarkan jenis pohon penyusun yang dominan (Bengen 2000).

Peran hutan mangrove selain ditinjau dari fungsi ekologinya yang membangun, juga diketahui memiliki nilai ekonomis yang mendorong kegiatan eksploratif, sehingga mangrove rawan terhadap perusakan (Hartoko 2015). Kawasan hutan mangrove merupakan suatu kawasan yang berfungsi sebagai jembatan antara lautan dengan daratan yang mempunyai fungsi ekologis sebagai pelindung garis pantai, mencegah abrasi air laut, habitat aneka biota perairan, tempat mencari makan, tempat asuhan dan pembesaran. Manfaat langsung dari keberadaan hutan mangrove di antaranya adalah hasil hutan kayu dan hasil hutan bukan kayu, sedangkan manfaat tidak langsungnya adalah jasa lingkungan, baik sebagai pengatur tata air, fungsi estetika, maupun sebagai penyedia oksigen dan penyerap karbon (Alongi 2015).

Kawasan hutan mangrove di pesisir Kelurahan Welai Timur dan Kelurahan Welai Barat adalah Kelurahan yang berada di Kabupaten Alor, Provinsi Nusa Tenggara Timur yang sejak tahun 2009 melalui Peraturan Bupati Nomor 6 Tahun 2009 ditetapkan sebagai salah satu kawasan areal KKLD (Kawasan Konservasi Laut Daerah) Kabupaten Alor. Kelurahan ini memiliki pesisir yang di domisili oleh ekosistem hutan mangrove. Berdasarkan hasil survei WWF Solor-Alor pada tahun 2014, ditemukan empat jenis mangrove kategori pohon yang mendominasi pesisir Kelurahan Welai Timur dan Kelurahan Welai Barat spesiesnya antara lain Rhizophora apiculata, Rhizophora mucronata, Avicennia alba dan Avicennia marina, dengan Indeks Nilai Penting (INP) tertinggi pada jenis Rhizophora apiculata yaitu sebesar 138,20\%, sementara nilai INP terendah terdapat pada jenis Avicennia marina dengan nilai $11,64 \%$.

Pengelolaan hutan mangrove di wilayah pesisir dan laut Kawasan Konservasi Laut Daerah (KKLD) Kabupaten Alor diperlukan karena telah terjadi degradasi lingkungan pesisir dan laut karena penebangan hutan mangrove secara tidak terkendali yang mengakibatkan kerusakan pada ekosistem mangrove. Khususnya di Kelurahan Welai Timur dan Kelurahan Welai Barat masih terdapat penebangan pohon mangrove untuk dijadikan sebagai lahan tambak, bahan bakar, dan bahan bangunan yang menyebabkan terjadinya kerusakan pada hutan mangrove sehingga fungsi hutan mangrove tidak berjalan dengan baik. Oleh karena itu, perlu adanya pengelolaan dan rehabilitasi yang baik untuk meningkatkan peran hutan mangrove di Kelurahan Welai Timur dan Kelurahan Welai Barat. Melihat dari latar belakang di atas maka perlu adanya penelitian tentang Persepsi Masyarakat terhadap Pengelolaan dan Rehabilitasi Hutan Mangrove Di Kelurahan Welai Timur Dan Kelurahan Welai Barat Kabupaten Alor untuk menunjang pengelolaan hutan Mangrove. 
DOI: $\underline{\text { https://doi.org/10.32663 }}$

\section{BAHAN DAN METODE}

Metode yang digunakan dalam penelitian ini adalah metode survei lapangan secara eksploratif. Penelitian eksploratif yaitu metode penelitian yang mengkaji dan mengungkapkan sesuatu dari lapangan sebagai suatu temuan-temuan yang dapat digunakan untuk menyusun model dan menarik kesimpulan (Nazir 1999). Adapun metode yang digunakan untuk pengambilan sampel yaitu metode purposive sampling, dimana metode pengambilan sampel tidak secara acak melainkan berdasarkan pertimbangan tertentu atau sengaja (Messerschmidt 1995). Pengambilan data kuesioner terdiri atas dua stakeholder yaitu pemerintah daerah Kabupaten Alor dan masyarakat pesisir Kelurahan Welai Timur dan Kelurahan Welai Barat.

Pemerintah Daerah yang dimaksud dalam penelitian ini adalah lembaga pemerintahan yang ikut berperan dalam program rehabilitasi mangrove antara lain: Dinas Kelautan Perikanan, Dinas Badan Lingkungan Hidup, Dinas Kehutanan dan Dinas Pemerintah Daerah, dengan jumlah populasi sebanyak 28 orang, sedangkan Masyarakat pesisir yang dimaksudkan dalam penelitian ini adalah masyarakat dewasa dengan kisaran umur 20-60 tahun, yang berdomisili di pesisir Kelurahan Welai Timur dan Kelurahan Welai Barat yang terkait dalam pengelolaan hutan mangrove. Data partisipasi masyarakat dalam rehabilitasi mangrove diperoleh melalui pengisian kuesioner yang diberikan kepada responden dalam lokasi penelitian. Data dari setiap Variabel diatas kemudian di analisis menggunakan Analisis Jalur (Path Analysis) dengan uji keakuratan data menggunakan uji Validitas, Reliabilitas, Structural Equation Modeling (SEM) SmartPLS, Outer Model (Outer relation atau measurement model), Combined loadings dan Cros - Loadings dan Inner Model (Inner relation atau structural model atau substantive theory) (Ghozali 2013 dan Ghozali 2015).

\section{Gambaran Umum Responden}

Responden yang diambil meliputi dua stakeholder yaitu pemerintah dan masyarakat dengan total responden sebanyak 58 orang. Total kuesioner yang disebarkan sebanyak 58 kuesioner, yaitu 28 untuk pemerintah daerah dan 30 untuk masyarakat. Kuesioner yang dikembalikan oleh responden dari kalangan masyarakat sebesar 30 kuesioner atau $52 \%$ sedangkan dari kalangan pemerintah daerah sebanyak 28 kuesioner atau $48 \%$.

\section{Waktu dan Lokasi Penelitian}

Penelitian ini dilakukan pada bulan Agustus sampai dengan bulan Oktober 2016. Tempat penelitian yaitu kawasan hutan mangrove di Pesisir Kelurahan Welai Timur dan Kelurahan Welai Barat, dimana terbagi atas Sembilan stasiun penelitian secara acak. Peta lokasi penelitian terlihat pada Gambar 1. 
DOI: $\underline{\text { https://doi.org/10.32663 }}$

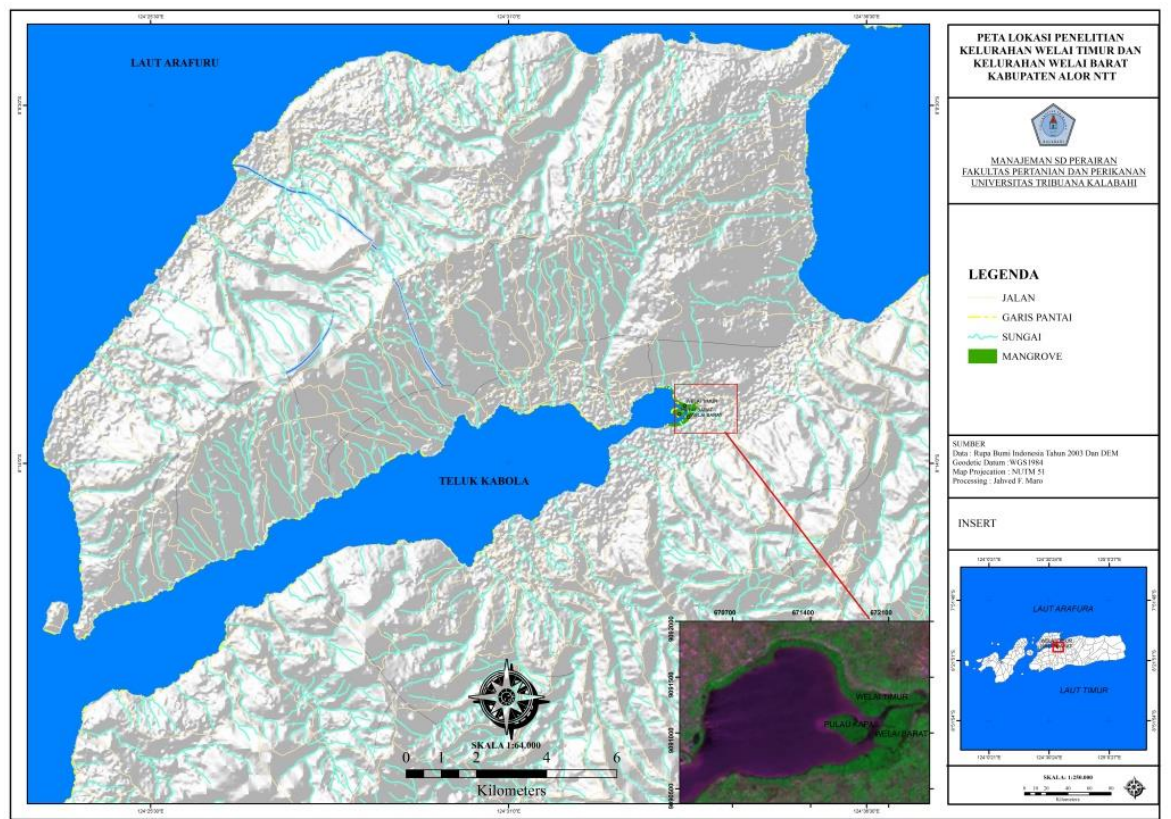

Gambar 1. Lokasi Penelitian

\section{Analisis Data}

Data kuesioner yang diperoleh dari responden dianalisis dengan menggunakan beberapa analisis, yaitu: Uji validitas, Uji reliabilitas, Uji Structural Equation Modeling (SEM) SmartPLS, Uji Outer Model (Outer relation atau measurement model), Combined loadings dan Cros Loading dan Inner Model (Inner relation atau structural model atau substantive theory) dengan Variabel yang di uji adalah responden. Jalur analisis terlihat pada Gambar 2.

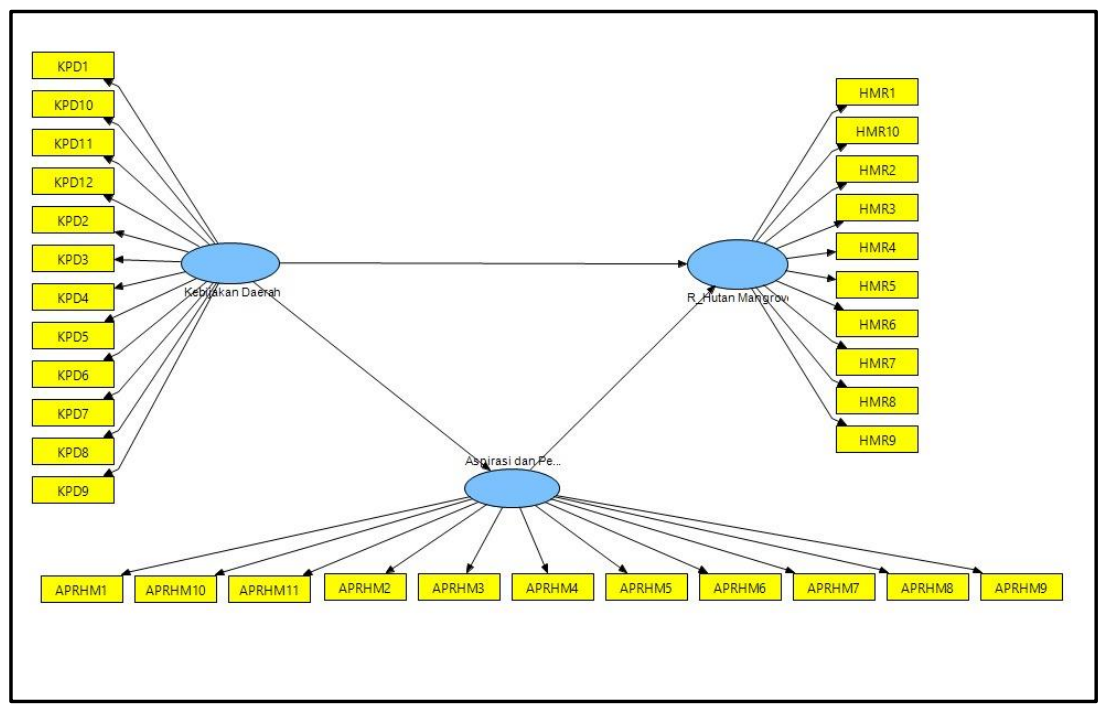

Gambar 2. Jalur analisis pengelolaan 
DOI: $\underline{\text { https://doi.org/10.32663 }}$

\section{HASIL DAN PEMBAHASAN}

Kelurahan Welai Timur dan Kelurahan Welai Barat merupakan 2 kelurahan diantara 175 desa/kelurahan di Kabupaten Alor yang memiliki wilayah berbatasan langsung dengan laut. Secara geografis, sebelah timur berbatasan dengan Desa Pantai Daere sebelah Barat berbatasan dengan Kelurahan Wetabua. Hasil penelitian menunjukkan vegetasi mangrove pada 9 stasiun di Kelurahan Welai Timur dan Kelurahan Welai Barat dengan total area plot sebesar $15700 \mathrm{~m}^{2}(1,57 \mathrm{Ha}) \mathrm{di}$ dominasi oleh jenis Rhizophora apiculata dengan kerapatan berkisar antara 18000 $98000 \mathrm{Ind} / \mathrm{Ha}$ dan kerapatan paling rendah ada pada jenis mangrove Avicennia alba dengan kerapatan 22000 - 32000 Ind/Ha. Indeks nilai penting (INP) pada semua stasiun penelitian ada pada jenis Rhizophora apiculata dengan presentase berkisar antara 54,045-239,230\%.

\section{Analisis Jalur (Path Analysis) Uji reliabilitas data kuesioner}

Suatu konstruk dapat dikatakan reliabel jika nilai Composite Reliability dan Cronbach's Alpha di atas 0,7 (Ghozali 2011), tetapi apabila nilai Cronbach's Alpha dibawah $\quad 0,7$ sedangkan nilai Composite Reliability diatas 0,7 maka data masih dapat dikatakan reliabel atau baik. Hasil uji reliabilitas disajikan pada Tabel 1.

Tabel 1. Hasil uji reliabilitas

\begin{tabular}{clccc}
\hline No & \multicolumn{1}{c}{ Variabel } & $\begin{array}{c}\text { Composite } \\
\text { reliability }\end{array}$ & $\begin{array}{c}\text { Cronbach's } \\
\text { alpha }\end{array}$ & Kriteria \\
\hline 1 & $\begin{array}{l}\text { Aspirasi dan peran masyarakat } \\
(\mathrm{X} 1)\end{array}$ & 0,934 & 0,924 & Baik \\
2 & $\begin{array}{l}\text { Kebijakan pemerintah daerah } \\
(\mathrm{X} 2)\end{array}$ & 0,916 & 0,908 & Baik \\
3 & Rehabilitasi mangrove (Y) & 0,941 & 0,930 & Baik \\
\hline
\end{tabular}

Variabel aspirasi dan peran masyarakat memiliki nilai Composite Reliability sebesar 0,934 dan nilai Cronbach's Alpha sebesar 0,924. Nilai keduanya lebih dari 0,7 sehingga dapat dikatakan semua pertanyaan variabel aspirasi dan peran masyarakat reliabel. Variabel kebijakan Pemerintah Daerah memiliki nilai Composite Reliability sebesar 0,916 dan nilai Cronbach's Alpha sebesar 0,908. Nilai keduanya lebih dari 0,7 sehingga dapat dikatakan semua pertanyaan variabel kebijakan daerah daerah reliable. Variabel rehabilitasi mangrove memiliki nilai Composite
Reliability sebesar 0,941 dan nilai Cronbach's Alpha sebesar 0,930. Nilai keduanya lebih dari 0,7 sehingga dapat dikatakan semua pertanyaan variabel rehabilitasi mangrove reliabel.

\section{Uji validitas data kuesioner}

Evaluasi validitas konvergen konstruk menggunakan indikator berupa average variance extracted (AVE) harus diatas 0,5 (Ghozali 2011). Ghozali (2008) menyatakan bahwa suatu indikator memenuhi uji validitas jika nilai loading factor lebih dari 0,7, sedangkan loading factor 0,5 sampai 0,6 masih dapat dipertahankan untuk model yang masih 
DOI: $\underline{\text { https://doi.org/10.32663 }}$

dalam tahap pengembangan. Hasil uji pada Tabel 2. average variance extracted (AVE) terlihat

Tabel 2. Hasil uji Average Variance Extracted (AVE)

\begin{tabular}{clcc}
\hline No & \multicolumn{1}{c}{ Variabel } & AVE & Kriteria \\
\hline 1 & Aspirasi dan peran masyarakat & 0,568 & Valid \\
2 & Kebijakan Daerah & 0,510 & Valid \\
3 & Rehabilitasi mangrove & 0,617 & Valid \\
\hline
\end{tabular}

Berdasarkan Tabel 2. dapat diketahui convergent validity dari masing-masing bahwa nilai AVE aspirasi dan peran indikator konstruk. Suatu indikator masyarakat adalah 0,568 , kebijakan daerah mempunyai reliabilitas yang baik jika memiliki nilai AVE 0,510, rehabilitasi nilainya lebih besar dari 0,70, sedangkan mangrove memiliki nilai AVE 0,617. nilai loading factor sebesar 0,50 sampai Semua pertanyaan dari variabel konstruk dengan 0,60 dapat dipertahankan untuk dapat dikatakan valid jika memenuhi syarat model yang masih dalam tahap AVE > 0,5. Variabel aspirasi dan peran pengembangan (Ghozali 2011). masyarakat, kebijakan daerah dan Berdasarkan kriteria ini, indikator reabilitasi mangrove memiliki nilai AVE indikator yang nilainya dibawah 0,5 harus lebih dari 0,5 sehingga semua pertanyaan didrop dari analisis. Hasil nilai loading konstruk valid.

Menguji Unidimentionalitas dari masing-masing konstruk dengan melihat

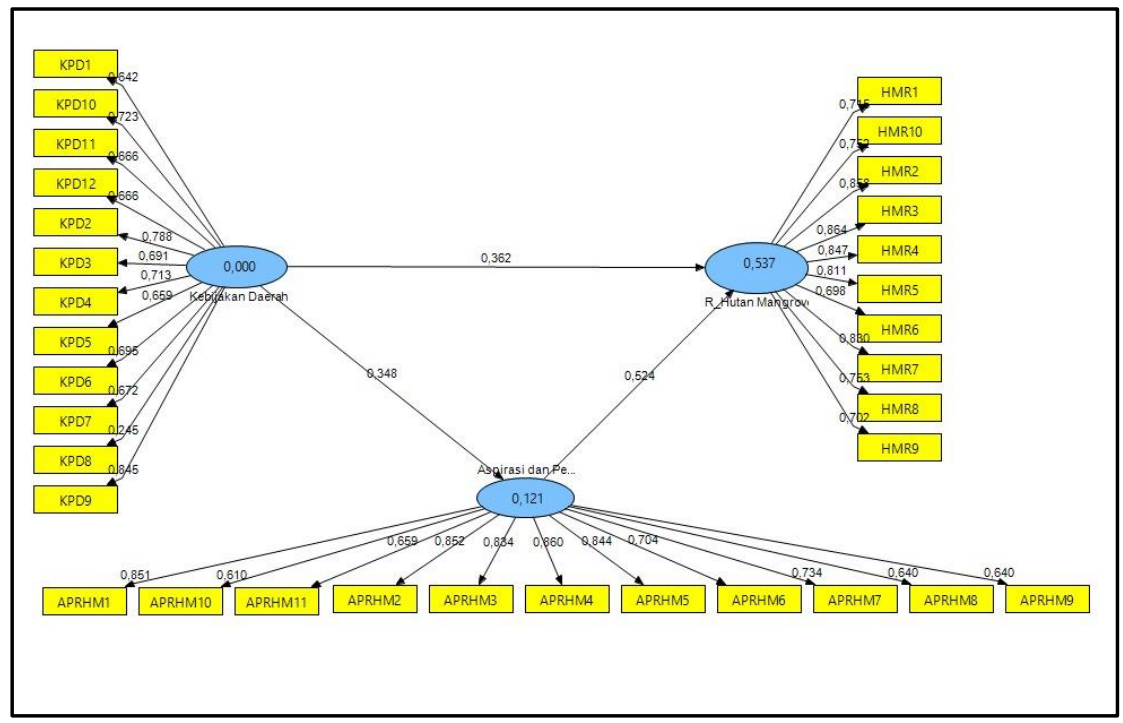

Gambar 3. Hasil Loading Factor

Keterangan :APRHM (Aspirasi dan Peran Masyarakat), HMR (Rehabilitasi Hutan Mangrove), KPD (Kebijakan Pemerintah Daerah)

Berdasarkan hasil loading factor pada kurang dari 0,50 yaitu 0,245 dan tidak Gambar 3., indikator KPD8 dikeluarkan signifikan, hal ini disebabkan karena dari model karena memiliki loading factor jawaban responden yang tidak akurat. 
DOI: $\underline{\text { https://doi.org/10.32663 }}$

Selanjutnya, di re-estimasi kembali dengan smartPLS 02 terlihat pada Gambar 4. membuang indikator KPD8, hasil output

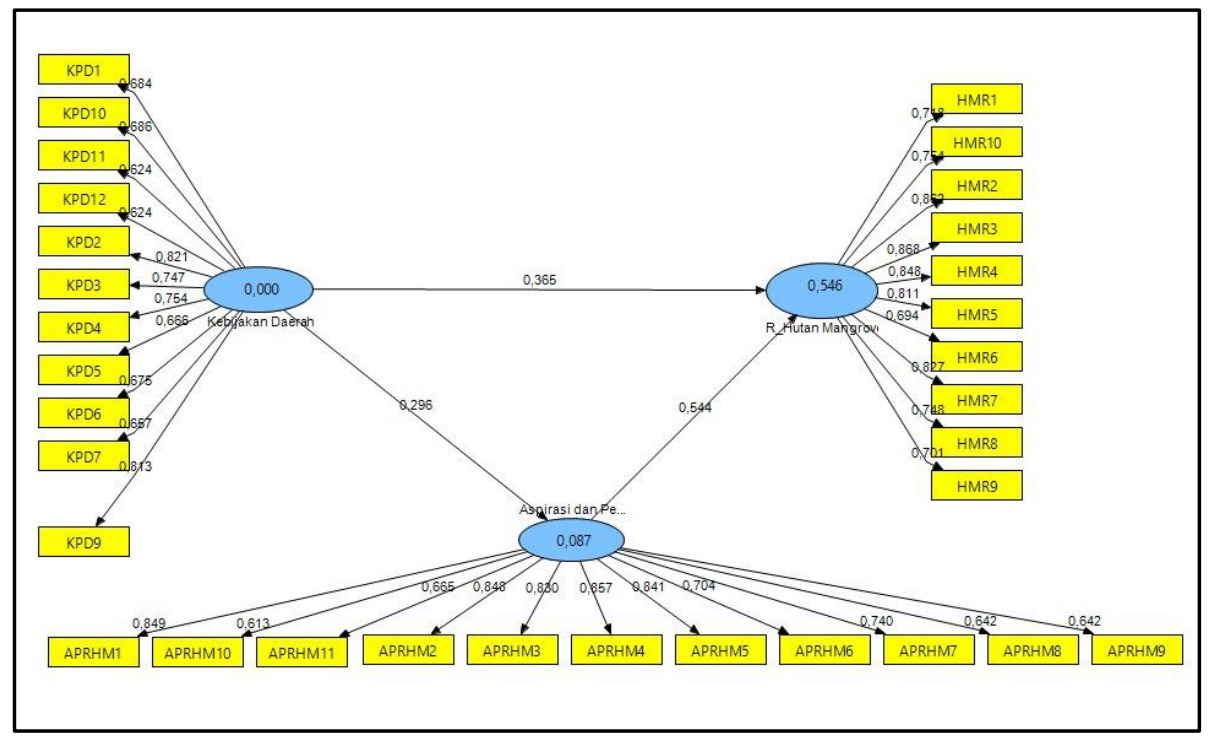

Gambar 4. Hasil re-estimasi Loading Factor

Keterangan :APRHM (Aspirasi dan Peran Masyarakat), HMR (Rehabilitasi Hutan Mangrove), KPD (Kebijakan Pemerintah Daerah)

Berdasarkan hasil re-estimasi loading factor pada Gambar 4. dapat dilihat nilai untuk konstruk semua variabel sebagian besar lebih dari 0,70. Tidak terdapat loading factor di bawah 0,50, sedangkan nilai loading factor yang berkisar antara 0,50 sampai 0,60 masih diperbolehkan. Oleh karena itu, dapat disimpulkan bahwa masing-masing indikator konstruk valid.

Hasil re-estimasi loading factor dengan model yang ditampilkan pada Gambar 4. menjelaskan bahwa variabel kebijakan Pemerintah Daerah berpengaruh secara langsung terhadap variabel rehabilitasi hutan mangrove dengan nilai loading factor sebesar 0,365, sedangkan variabel kebijakan daerah secara tidak langsung berpengaruh terhadap variabel aspirasi dan peran masyarakat dengan nilai loading factor sebesar 0,296 dan yang terakhir variabel aspirasi dan peran masyarakat berpengaruh secara langsung terhadap variabel rehabilitasi hutan mangrove dengan nilai loading factor sebesar 0,544 .

Berdasarkan hasil nilai re-estimasi loading factor, nilai terbesar ada pada variabel aspirasi dan peran masyarakat terhadap variabel rehabilitasi mangrove dibandingkan dengan kedua variabel lainya.

Menilai inner model atau structural model Inner model atau stuctural model menggambarkan hubungan antara variabel laten dimana setiap variabel harus memiliki nilai T-hitung > T-tabel 1,96. Dalam penelitian ini, terdapat 3 hubungan yang diteliti yaitu hubungan antara kebijakan daerah terhadap rehabilitasi mangrove, aspirasi dan peran masyarakat terhadap rehabilitasi mangrove, serta kebijakan daerah terhadap aspirasi dan peran masyarakat. Nilai hubungan antar variabel 
DOI: $\underline{\text { https://doi.org/10.32663 }}$

dapat dilihat pada hasil uji path coefficients yang tersaji pada Tabel 3 .

Tabel 3. Hasil Uji Path Coefficients

\begin{tabular}{lcccc}
\hline \multicolumn{1}{c}{ Variabel } & $\begin{array}{c}\text { Original } \\
\text { Sample } \\
(\mathbf{0})\end{array}$ & $\begin{array}{c}\text { Sample } \\
\text { Mean } \\
(\mathbf{M})\end{array}$ & $\begin{array}{c}\text { Standars } \\
\text { Deviation } \\
(\mathbf{S T D E V})\end{array}$ & $\begin{array}{c}\text { T } \\
\text { Statistics } \\
(\mathbf{0} / \text { STDEV) }\end{array}$ \\
\hline $\begin{array}{l}\text { Aspirasi dan Peran Masyarakat-> } \\
\text { Rehabilitasi Mangrove }\end{array}$ & 0,544 & 0,543 & 0,046 & 11,760 \\
$\begin{array}{l}\text { Kebijakan Daerah -> Aspirasi dan } \\
\text { Peran Masyarakat }\end{array}$ & 0,295 & 0,322 & 0,068 & 4,319 \\
$\begin{array}{l}\text { Kebijakan Daerah -> Rehabilitasi } \\
\text { Mangrove }\end{array}$ & 0,364 & 0,371 & 0,056 & 4,319 \\
\hline
\end{tabular}

Berdasarkan hasil uji path coefficients dapat disimpulkan bahwa terdapat tiga hubungan signifikan dimana T-hitung lebih besar dari T-tabel $(>1,96)$ dengan tingkat signifikansi $<0,05$. Tiga hubungan yang signifikan tersebut dapat dijelaskan sebagai berikut: Pertama, hubungan aspirasi dan peran masyarakat terhadap rehabilitasi mangrove memiliki nilai koefisien sebesar 0,544 dengan nilai T-hitung sebesar 11,760 $(>1,96)$. Kedua, kebijakan daerah terhadap aspirasi dan peran masyarakat memiliki nilai koefisien sebesar 0,295 dengan nilai T-hitung sebesar sebesar 4,319 (>1,96). Ketiga, kebijakan daerah terhadap rehabilitasi mangrove memiliki nilai koefisien sebesar 0,364 dengan nilai $\mathrm{T}$ hitung sebesar 4,319 (>1,96).

Hasil uji path coefficients pada Tabel 3. menunjukkan bahwa variabel yang memiliki nilai koefisien dan nilai T-hitung terbesar adalah aspirasi dan peran masyarakat terhadap rehabilitasi hutan mangrove dibandingkan dengan variabel kebijakan daerah terhadap aspirasi dan peran masyarakat, dan juga kebijakan daerah terhadap rehabilitasi hutan mangrove.
Hasil uji Discriminant validity, Cross Loading dan Path Coefficients hubungan antara kendala-kendala yang berpengaruh dalam rehabilitasi hutan mangrove di kawasan mangrove Kelurahan Welai Timur dan Kelurahan Welai Barat menunjukkan bahwa variabel aspirasi dan peran masyarakat terhadap variabel rehabilitasi hutan mangrove memiliki nilai hubungan yang besar dibandingkan variabel kebijakan Pemerintah Daerah terhadap variabel rehabilitasi hutan mangrove di kawasan mangrove Kelurahan Welai Timur dan Kelurahan Welai Barat. Sehingga dapat diasumsikan kendala-kendala dalam rehabilitasi hutan mangrove di pesisir Kelurahan Welai Timur dan Kelurahan Welai Barat Kabupaten Alor adalah kurangnya aspirasi dan peran masyarakat dalam rehabilitasi hutan mangrove.

Pesisir Kelurahan Welai Timur dan Kelurahan Welai Barat adalah Kelurahan yang termasuk di dalam Kawasan Konservasi Laut Daerah (KKLD) Kabupaten Alor sehingga ekosistem mangrove di kawasan ini penting untuk dilindungi agar fungsi ekologis, biologis dan ekonomi bisa berjalan dengan baik 
DOI: $\underline{\text { https://doi.org/10.32663 }}$

demi keberlangsungan kawasan dan Ghozali, I. 2013. Aplikasi Analisis organisme yang hidup didalamnya.

\section{KESIMPULAN}

Hasil penelitian melalui uji Reliabilitas, Validitas, Loading Factor dan Path Coefficients menunjukkan bahwa kendala-kendala yang sangat berpengaruh dalam pengelolaan rehabilitasi hutan mangrove di kawasan mangrove Kelurahan Welai Timur dan Kelurahan Welai Barat Kabupaten Alor adalah aspirasi dan peran masyarakat dalam rehabilitasi hutan mangrove. Kurangnya aspirasi dan peran masyarakat tersebut dapat disebabkan karena kurangnya kontrol dari pihak pemerintah.

\section{DAFTAR PUSTAKA}

\section{Bengen. 2000. Pedoman Teknis Pengenalan} dan Pengelolaan Ekosisitem Mangrove. Pusat Kajian Sumberdaya Pesisir dan Lautan. Institut Pertanian Bogor.

Ghozali, I., Letan, H. 2015. "Partial Least Squares : Konsep, Teknik dan Aplikasi Menggunakan Program SmartPLS 2.0 M3. Badan Penerbit Universitas Diponegoro. Semarang. Multivariante Dengan Program IBM SPSS 21. Badan Penerbit Universitas Diponegoro. Edisi 7. Semarang.

-------. 2011. Structural Equation Modeling. Metode Alternatif Dengan Partial Least Square (PLS). Badan Penerbit Universitas Diponegoro. Edisi 2. Semarang.

Hartoko A. Cahyaningrum, ST.. Febrianti, DA. Arifianto, D. Suryanti. 2015. Carbon Biomass Algorithms Development for Mangrove Vegetation in Kemujan, Parang Island Karimunjawa National Park and Demak Coastal Area - Indonesia. Universitas Diponegoro Semarang. Jurnal Science Direct 23 : 39-47.

Messerscmidt, DA. 1995. Rapid Appraisal for Community Foresty. Methodology Series. International Institute for Environment and Development. UKLondon.

Nazir, M. 1999. Metode Penelitian. Ghalia Indonesia. Jakarta.

World Wide Fund for Nature Solor-Alor. 2014. Laporan Survey Vegetasi Mangrove di Kabupaten Alor. 